\title{
ПЕРВАЯ СТЕПЕНЬ
}

\section{А.Б. СОРБАЛЭ* \\ ВЛАСТЬ И АВТОРИТЕТ В ЕВРОПЕЙСКОМ СОЮЗЕ: «ЦАРИ ГОРЫ» И «БОЛЬШИЕ КОАЛИЦИИ»}

Аннотация. Как распределяются власть и авторитет в Европейском союзе? Какую роль играет государственная состоятельность в рамках отношений между уровнями власти в ЕС? Автор статьи стремится ответить на эти вопросы, обращаясь к двум ключевым подходам к анализу Европейского союза как многоуровневой системы управления: структурно-акторному подходу и подходу консоциативной демократии. В то время как сторонники структурно-акторного подхода воспринимают ЕС как иерархичную систему, где один из уровней власти всегда оказывается в положении доминирования и может диктовать свои правила игры, теоретиков европейского консоциативизма больше интересуют вопросы, связанные с процессом принятия решений в условиях «больших коалиций», горизонтальной и вертикальной подотчетности и демократического дефицита.

Ключевые слова: власть; авторитет; структурно-акторный подход; консоциативная демократия; государственная состоятельность.

Для цитирования: Сорбалэ А.Б. Власть и авторитет в Европейском союзе: «Цари горы» и «большие коалиции» // Политическая наука. - 2019. - № 3. C. 200-221. - DOI: http://www.doi.org/10.31249/poln/2019.03.11

* Сорбалэ Алексей Борисович, аспирант Аспирантской школы по политическим наукам Научно-исследовательского университета Высшая школа экономики (Санкт-Петербург, Россия), e-mail: asorbale@hse.ru

(C) Сорбалэ А.Б., 2019

DOI: $10.31249 /$ poln/2019.03.11 


\section{Введение}

В классических теориях международных отношений государства рассматриваются как единственные акторы, участвующие в распределении власти в рамках международной политической системы. Негосударственным образованиям, прежде всего международным организациям, в данных теориях отведена относительно несущественная роль. Реалисты говорят о международных организациях как об акторах, которые «существуют в международной системе отношений, но не могут оказать существенного влияния на то, что происходит в мире» [Morgenthau, 1950]. В свою очередь, для неореалистов международные организации играют инструменталистскую роль арен для взаимодействия главных акторов международных отношений - национальных государств [Jervis, 1978; Waltz, 1986]. Представители либеральной и неолиберальной теорий придерживаются тех же взглядов на роль международных организаций, что и их идеологические противники: для последователей Иммануила Канта [Kant, 1970], Роберта Кохейна [Keohane, 2005] и Джозефа Ная [Nye, 1971] международные организации являются удобными площадками для взаимовыгодного сотрудничества между государствами, и при этом не имеют существенной институциональной и нормативной силы.

По мнению структуралистов [Haas, 1998; Keohane, Moravcsik, Slaughter, 2000; Checkel, 2001; Tallberg, 2002], картина эмпирической реальности, которую предлагает Европейский союз, отличается от рассматриваемой классиками международных отношений. В представлении структуралистов национальный и наднациональный уровень в рамках ЕС как бы меняются местами, поскольку в нормативном отношении право Европейского союза стоит выше права национальных государств, и страны - члены Европейского союза обязаны следовать правилам игры, определяемым Брюсселем, и передавать на наднациональный уровень часть полномочий, которые традиционно считались их вотчиной как «унитарных рациональных акторов» [Waltz, 1986, p. 331]. И все же в структурном подходе можно обнаружить один из важнейших постулатов спора между неореалистами и неолибералами - положение о господстве и подчинении, или патрон-клиентских отношениях. Так, Алек Стоун Свит и Вэйн Сандхольц отмечают, что с точки зрения полномочий и авторитета уровень ЕС находится 
«выше» уровня входящих в него государств [Sandholtz, Stone Sweet, 1997, p. 300].

Альтернативный взгляд на природу распределения власти и авторитета в рамках Европейского союза представляют такие авторы, как Петр Хилле и Кристоф Книлл [Hille, Knill, 2006], Димитер Тошков [Toshkov, 2007] и Флориан Траунер [Trauner, 2009]. Для них «царями горы», т.е. игроками, обладающими наибольшими властными полномочиями в рамках Европейского союза, выступают не нормативные регуляторы ЕС, но представители государств-членов в национальных и наднациональных органах власти. По мнению Рональда Митчелла [Mitchell, 1994] и Джеймса Фирона [Fearon, 1998], национальные игроки способны самостоятельно формировать политические курсы и «проталкивать» наиболее выгодную интерпретацию политической повестки. Подход, ставящий во главу угла национальных политических акторов, в противовес структурному подходу зачастую называют акторным.

Структурно-акторный подход, апеллирующий к старому спору между неореалистами и неолибералами, зачастую подвергается критике за редукционизм и иерархизацию отношений между странами - членами ЕС и наднациональными институтами. По мнению Вальтера Карлснаеса [Carlsnaes, 1992, p. 247], вопросы, связанные с распределением власти, многоуровневым авторитетом и подотчетностью, не сводятся к выяснению отношений о «главенстве» того или иного уровня принятия решений в структуре Европейского союза. Мэтью Габель [Gabel, 1998], Руди Андевег [Andeweg, 2000], Маттиас Богаардс [Bogaards, 2002], Петер Краус [Kraus, 2006] и многие другие авторы демонстрируют, что архитектура принятия решений в ЕС наиболее близка к так называемой сообщественной, или консоциативной (consociational) демократии. Томас Банчоф и Митчелл Смит [Legitimacy and the European Union... 2005] отмечают, что ЕС всегда стремился к максимально широкой и глубокой интеграции, которая должна завершиться созданием «Европейской федерации». Федерация как тип административно-территориального устройства, даже со спецификой европейской «неофедерации» [Volpi, 2011], не предполагает доминирования одного из уровней власти, но направлена на выработку правил игры, которые бы устраивали всех потенциальных ветоигроков. 
В дискуссии о распределении власти и авторитета в рамках Европейского союза как представители структурно-акторного подхода, так и сторонники теории европейской консоциативной демократии зачастую обращаются к концепту государственной состоятельности (state capacity). Оба подхода рассматривают государственную состоятельность как способность государства использовать имеющиеся ресурсы и эффективно аллоцировать их для осуществления определенного политического курса [Between power and plenty... 1978; Bringing the state back in, 1985; Tsebelis, 1995; Linos, 2007]. Тем не менее в двух рассматриваемых исследовательских подходах можно обнаружить существенное различие в интерпретации государственной состоятельности в привязке к проблеме властных отношений и авторитета. Для структурноакторного подхода государственная состоятельность - это прежде всего репрезентация структурных характеристик государств - членов ЕС или результат стратегических решений национальных и наднациональных политических акторов [Paraskevopoulos, 1998; Haas, 1998; Keohane, Moravcsik, Slaughter, 2000; Checkel, 2001; Tallberg, 2002]. В свою очередь, приверженцы подхода европейской консоциативной демократии рассматривают государственную состоятельность как способность «большой коалиции» (grand coalition), включающей всех значимых политических акторов, принимать и имплементировать политические решения, определяющие логику функционирования всего Европейского союза, в условиях правил игры консоциативной системы [Consociational Democracy, 1974; Horowitz, 1985; Reilly, 2012].

Первая часть статьи посвящена операционализации концепта государственная состоятельность в контексте исследования власти и авторитета в Европейском союзе. Во второй части работы мы рассматриваем два основных подхода к анализу властных отношений в рамках ЕС: структурно-акторный подход и подход консоциативизма, - и делаем упор на слабых местах этих двух подходов. Последняя часть исследования посвящена выводам и возвращает нас к вопросу о взаимосвязи государственной состоятельности и проблем авторитета и властных отношений внутри Европейского союза. 


\section{Государственная состоятельность и Европейский союз: два подхода к операционализации}

Прежде чем переходить к рассмотрению теоретических подходов к проблеме власти и авторитета в ЕС, необходимо понять, что именно подразумевают исследователи-европеисты под государственной состоятельностью.

В научной литературе принято выделять два варианта операционализации концепта государственная состоятельность. В первом случае речь идет о государственной состоятельности как способности государства использовать имеющиеся ресурсы для имплементации политических решений и иной государственной деятельности [Sustainable Democracy, 1995; Haas, 1998; Simmons, 1998]. Во втором варианте операционализации государственная состоятельность предполагает не только использование государством имеющихся ресурсов, но и достижение соглашения, выгодного всем ведущим игрокам на национальной политической арене, которое позволяет рационально и эффективно расходовать ресурсы для осуществления определенного политического курса [Between power and plenty... 1978; Bringing the state back in, 1985; Tsebelis, 1995; Linos, 2007]. В рамках этого подхода особую роль играют национальные вето-акторы и институциональная структура в целом.

Помимо этого, существуют исследования, которые стремятся комбинировать ресурсно-ориентированный и акторо-ориентированный подходы к пониманию государственной состоятельности [Стукал, Хавенсон 2012; Мельвиль, Стукал, Миронюк, 2012].

Исследования, посвященные государственной состоятельности в контексте распределения властных полномочий и авторитета в Европейском союзе, также могут быть разделены на те, которые подчеркивают важность объема и разнообразия имеющихся у государства ресурсов, и те, где аналитический фокус смещен в пользу аллокации ресурсов силами национальных и наднациональных акторов. Первый тип исследований связывает государственную состоятельность со способностью наднациональных нормативных регуляторов заставить страны-члены соблюдать право ЕС или со способностью стран-членов провести свой вариант определенного политического курса [Haas, 1998; Fearon, 1998; Checkel, 2001; Tallberg, 2002]. Другие авторы настаивают на том, что государствен- 
ная состоятельность в рамках Европейского союза гарантирует стабильность работы консоциативных институтов европейской демократии, прежде всего «больших коалиций» и институтов, обеспечивающих горизонтальную и вертикальную подотчетность [Golub, 1996; Jordan, 2000; Burgess, 2000; Cooper, 2006].

Две представленные выше концепции государственной состоятельности во многом определяют логику построения теоретических моделей, которые анализируют процессы распределения авторитета и власти в Европейском союзе. Как мы увидим ниже, исследователи-европеисты по-разному понимают и интерпретируют роль национальных и наднациональных акторов и институтов в управленческой архитектуре европейской политии.

\section{Власть и авторитет в Европейском союзе: иерархия против консоциативизма}

Теории, которые стремятся дать характеристику властным отношениям в рамках Европейского союза, можно условно разделить на те, которые определяют отношения между национальным и наднациональным уровнями принятия решений как иерархические, и те, которые описывают управленческую архитектуру ЕС в терминах теории консоциативной демократии.

\section{Структурно-акторный подход: кто «царь горы»?}

Исследователи, берущие за основу структурно-акторный подход, рассматривают отношения между национальными государствами - членами ЕС и институтами Европейского союза как иерархические: в выстраиваемых ими моделях преимущество «нормативного диктата» всегда на стороне одной из сторон, в то время как вторая сторона вынуждена уступать требованиям условного принципала.

Обратимся к теориям, которые ставят на вершину иерархических отношений в Европейском союзе наднациональные нормативные регуляторы. Петер Хаaс [Haas, 1998], Йонас Талльберг [Tallberg, 2002], Роберт Кохейн и соавторы [Keohane, Moravcsik, Slaughter, 2000] пишут, что пространство для маневра и «торгов» 
(bargaining) для стран-членов ограничено правилами игры, установленными институтами ЕC, в связи с чем страны, выходящие за пределы «поля торгов» [Keohane, Moravcsik, Slaughter, 2000], подвергаются наказанию со стороны наднациональных регулирующих структур. В свою очередь, Ева Хайдбредер [Heidbreder, 2011] и Джеффри Чекел [Checkel, 2001] считают, что страны - члены EC подчиняются требованиям институтов ЕС, потому что они «должны» подчиняться закону, а не потому что это им выгодно. В исследованиях данных авторов директивы ЕС выступают не в роли «кнута» или «пряника», а в роли нормативного идеала, которому государство должно подчиняться вследствие установившейся традиции.

Альтернативный подход к исследованию проблем власти и авторитета в ЕС переворачивает иерархическую модель, построенную Хаасом, Талльбергом и Кохейном, и выдвигает на первый план страны - члены ЕС и их стратегии поведения. Джеймс Фирон [Fearon, 1998] утверждает, что государства, входящие в состав ЕС, участвуют в «торгах» для того, чтобы подкорректировать общеевропейскую повестку в свою пользу. Многие европеисты, берущие за основу положение Фирона о «торгах», понимают государственную состоятельность в рамках Европейского союза как способность национальных политических акторов найти точку равновесия, которая бы максимизировала выигрыши от принятия общеевропейских правил игры на наднациональном уровне, и использовать имеющиеся ресурсы для приближения результата «торгов» к этой выигрышной точке [Mitchell, 1994; Mendrinou, 1996; Paraskevopoulos, 1998].

Из краткого обзора исследований структурно-акторного блока становится понятно, что данные работы сводят отношения между условным «центром» ЕС и странами-членами до базовой модели иерархии «принципал - агент». Государственная состоятельность в контексте, предлагаемом апологетами структурно-акторного подхода, превращается из условия стабилизации многосоставной политической системы в инструмент «продавливания» решения в обход всех остальных вето-акторов. Редукционистский взгляд к проблемам власти и управления, взятый на вооружение авторами структурно-акторного подхода, справедливо подвергается критике со стороны множества исследователей [Bogaards, Crepaz, 2002; Kaiser, 2002; Jolly, 2005; Costa, Foret, 2005]. В следующем блоке мы пред- 
ставим альтернативный подход к исследованию властных отношений и авторитета в рамках Европейского союза, который отвергает упрощенные схемы структурно-акторного подхода и фокусируется на проблемах функционирования ЕС как консоциативной системы принятия решений.

\section{Консоциативная модель: «большие коалиции» и большие разломы}

Эмпирическая реальность процесса принятия решений в Европейском союзе демонстрирует, что архитектура институтов ЕС не сводится к противостоянию элитных групп национального и наднационального уровня и «борьбе компетенций» [Billiet, 2006; Adler-Nissen, 2014]. Чтобы обосновать нерелевантность построений структурно-акторного подхода, достаточно вспомнить два кейса. Первый кейс - это попытка принятия так называемой Европейской конституции (Constitution for Europe), провалившаяся изза протестного голосования во Франции и Нидерландах в 2005 г. [Jérôme, Vaillant, 2005; Toonen, Steunenberg, 2006; Hug, Schulz, 2007]. Второй кейс - это инициатива заключения соглашения о Трансатлантическом торговом и инвестиционном партнерстве (Transatlantic Trade and Investment Partnership, TTIP) между Европейским союзом и США, которая была заблокирована на уровне Бельгийской Валлонии [Gheyle, De Ville, 2019]. Эти два случая демонстрируют, что модель принятия политических решений в Европейском союзе не ставит более низкие уровни власти перед фактом необходимости принятия и имплементации соответствующего решения, но включает акторов данных «низовых» уровней в дискуссию и тем самым повышает риски наложения вето на предлагаемую инициативу. Иными словами, формирование актуальных политических курсов в Европейском союзе в большей степени схоже с аналогичными процессами в многосоставных федерациях, чем в системах имперского типа, где последнее слово всегда остается за центральным нормативным регулятором. Именно эту мысль пытаются донести такие авторы, как Мэтью Габель [Gabel, 1998], Руди Андевег [Andeweg, 2000], Маттиас Богаардс [Bogaards, 2002], Петер Краус [Kraus, 2006], Геральд Шнайдер и соавторы [Schneider, Finke, Baltz, 2007]. 
Критики структурно-акторного подхода в своих размышлениях отталкиваются от модели сообщественной, или консоциативной демократии, которая была предложена Арендом Лейпхартом [Lijphart, 1969]. Лейпхарт выделяет четыре условия сообщественной демократии: 1) «большую коалицию» (grand coalition), включающую в себя, в противовес минимальной правящей коалиции (minimal-size coalition), представителей всех заинтересованных социальных групп, 2) право взаимного вето, которое может использоваться любой из групп, входящей в «большую коалицию», 3) принцип пропорциональности в сферах политического представительства и управления и 4) принцип сегментальной автономии (segmental autonomy), обеспечивающий независимость законодателей составных частей сообщественной демократии от интервенции со стороны законодателей более высокого уровня [Lijphart, 1969, p. 110-132].

Процесс принятия решений и распределения властных полномочий в консоциативной демократии неразрывно связан с проблемой государственной состоятельности. Чтобы понять суть этой взаимосвязи, необходимо сделать шаг назад и обратиться к предварительныл условиям этой модели распределения власти. Базовый фактор, обеспечивающий большую часть успеха реализации проекта сообщественной демократии, - отсутствие конфликта [Noel, 2005; Simonsen, 2005; Horowitz, 2008; Taylor, 2009]. Вторым важным условием, которое обеспечивает эффективность и общественную значимость работы консоциативных институтов, является наличие в обществе «глубоких разломов» (deep divides) [Selway, Templeman, 2012; Deliberating across... 2014]. Эти разломы, или линии разделения могут проходить по различным границам: религиозным, этническим, культурным, урбанизационным и даже идеологическим [Butenschøn, 1985; Smooha, Hanf, 1992; Haddad, 2009; Garry, 2014]. Наконец, власть в государстве, где происходит попытка институционально укоренить правила игры сообщественной демократии, должна быть «разделена, а не монополизирована, должна делегироваться, а не быть централизована» [Bogaards, 2006, p. 119]. Иными словами, должны соблюдаться основные принципы автономности и сфер ответственности субъектов многосоставной политической системы, о которых писал Лейпхарт.

Вышеописанные условия и принципы являются лишь моделью и своеобразным know how для политических элит, которые 
под давлением общества и внутренней и внешней конъюнктуры находятся в поиске источников стабилизации глубоко разделенных обществ (deeply divided societies), но не рецептом успеха этих государств. По словам Маттиаса Богаардса, институты сообщественной демократии, позволяющие стране избежать конфликта, могут нести в себе угрозу политического тупика и глобального политического кризиса в случае, если участникам политического процесса не удастся договориться о решении, которое станет идеальной точкой равновесия для всех заинтересованных сторон [Bogaards, 2006, p. 119]. Работы Клауса Армингеона [Armingeon, 2002] и Андре-Поля Фроньера [Frognier, 1988] подтверждают этот тезис. Их работы демонстрируют тот факт, что государства с укоренившейся системой сообщественных институтов сталкиваются с большими трудностями при реализации политических решений, чем страны, чья система управления и распределения властных полномочий не имеет признаков консоциативной.

Критерии, которые первоначально брались за основу для анализа институциональной архитектуры глубоко разделенных обществ, довольно быстро были приняты на вооружение европеистами. Сначала Герхард Лембрух [Consociational Democracy... 1974], Дональд Горовиц [Horowitz, 1985] и Бен Рейли [Reilly, 2012], а за ними и многие другие авторы стали утверждать, что по своей институциональной структуре и объему полномочий (включая право взаимного вето), который распределяется между странами-членами и наднациональными регулирующими институтами, EC близок к консоциативной модели. Майкл Бургесс подчеркивает, что процесс принятия решений в Европейском союзе опирается на механизмы сотрудничества, задействующие как межправительственный, так и наднациональный уровень. При этом такие институты, как Европейский суд и Европейская комиссия, занимают очень сильную институциональную позицию по отношению к странам членам Союза, и решения этих институтов имеют приоритет над национальным законодательством [Burgess, 2000, p. 29].

В центре исследований, посвященных вопросам распределения власти в рамках ЕС, в большинстве случаев находится принцип субсидиарности. Принцип субсидиарности, впервые официально закрепленный в Договоре о Европейском союзе (Treaty on European Union, TEU), прямо говорит, что если какой-либо вопрос может быть решен на определенном уровне принятия решений, то 
он не должен передаваться на более высокий уровень власти [TEU]. Разделение компетенций между уровнями власти в Европейском союзе получило широкое отражение в работах авторовевропеистов. Эндрю Джордан, анализируя принятие экологических стандартов странами - членами ЕС, упирает на то, что стандарты не просто «спускаются» Брюсселем и принимаются странами - членами EC, но обсуждаются между национальным и наднациональным уровнями власти, которые руководствуются имеющимися у них компетенциями для отстаивания своей позиции. Результатом этого обсуждения становится формирование «единой» европейской политики, удовлетворяющей интересы всех акторов, которые принимали участие в обсуждении [Jordan, 2000].

Выше мы отмечали, что главный раскол между теориями структурно-акторного подхода базировался на вопросе о том, под каким углом смотреть на отношения между уровнями власти в ЕС. Теоретики структурно-акторного подхода стремились определить своеобразного «царя горы»: для ряда исследователей в качестве единого и неоспоримого авторитета выступали нормативные регулирующие институты Европейского союза, а другие авторы подчеркивали способность стран - членов ЕС самостоятельно диктовать свои условия Брюсселю. Вопросы, волнующие сторонников идеи европейской сообщественной демократии, не связаны с иерархическими отношениями между уровнями принятия решений, но апеллируют к базовой критике концепции консоциативизма в целом.

Большинство критиков сообщественной демократии сходятся во мнении, что консоциативизм по своей сути является элитистской формой принятия решений. Филипп Родер и Дональд Ротшильд отмечают, что консоциативная демократия ограничивает массовое участие граждан в политике и сводит принятие решений до соглашений между отдельными элитными группами [Sustainable peace... 2005, p. 6]. Пол Диксон поддерживает эту идею, отмечая, что сообщественный тип демократии страдает от «недостатка качества демократии (democratic quality)», что выражается в конструировании институциональных препятствий для граждан, стремящихся участвовать в политике напрямую, а не через представителей, выражающих их интересы [Dixon, 2012, p. 109]. В работах, посвященных архитектуре сообщественной демократии в 
Европейском союзе, проблема недостатка качества демократии получила название демократического дефицита.

Критики консоциативной системы принятия решений в Европейском союзе задаются вопросом о том, позиция каких институтов наиболее сильная - институтов, которые напрямую выбираются гражданами Европейского союза (Европейский парламент), или институтов, которые формируются под эгидой его странчленов (Совет министров и Европейская комиссия). Петер Краус обозначает этот вопрос как дихотомический: что такое Европейский союз - союз стран или союз народов? [Kraus, 2006, p. 209]. $\mathrm{B}$ то время как с формальной точки зрения и Европейский парламент, и Европейская комиссия являются институтами, формально независимыми от влияния стран - членов Европейского союза и должны «выражать интересы всего Союза» [Kohler-Koch, 1994, p. 168], большое количество исследований демонстрируют, что депутаты Европарламента и еврокомиссары крайне подвержены влиянию национальной повестки [Attina, 1990; Moravcsik, 1991; Peters, 1994; Kohler-Koch, 1997; Richardson, 2000]. За последние два десятилетия в среде исследователей, критикующих консоциативную архитектуру управления в Европейском союзе, укоренилось мнение, что в ЕС «не осталось места для избирателей» [Treib, 2014, p. 1544], поскольку процесс принятия политических решений происходит «исключительно благодаря соглашениям между влиятельными еврогруппами» [Treib, 2014, p. 1546]. С этой точки зрения критика консоциативной модели распределения власти в Европейском союзе схожа с критикой иерархической модели, которую описывают апологеты структурно-акторного подхода: обе модели практически не оставляют места для избирателей и их предпочтений, которые обеспечивают политическую повестку для инкумбентов на национальном и наднациональном уровнях и формируют структуру вертикальной подотчетности [Kraus, 2006, p. 211].

Дискуссия о демократическом дефиците вновь возвращает нас к проблеме принятия решений в многосоставных и глубоко разделенных обществах. Примеры голосования за Конституцию ЕС и провал проекта соглашения о зоне свободной торговли с США демонстрируют, что институционализированное право взаимного вето может привести к откладыванию или даже отмене принятия решения, что влияет на всю политическую структуру 
Европейского союза. В этих условиях, как отмечает Пол Магнетте, национальные и наднациональные акторы стремятся снизить политическую неопределенность и минимизировать возможность блокировки решений, имеющих «важную роль для функционирования Союза как политической системы» [Magnette, 2003, p. 151]. Практики лоббизма и договоренностей между акторами европейского политического процесса, транслирующие интересы национальных акторов на наднациональный уровень принятия решений, далеки от демократических и снижают эффективность подотчетности избранных представителей своему электорату, но, как отмечает Герхард Лембрух, вполне вписываются в логику функционирования консоциативных демократий, которые «редуцируют демократические принципы в пользу корпоративистской эффективности» [Lehmbruch, 1993].

\section{Заключение}

Мы описали два подхода к анализу проблем распределения и реализации властных полномочий и авторитета в Европейском союзе: структурно-акторный и консоциативный. Структурноакторный подход ищет в структуре ЕС условного «царя горы» и берет за основу установки о линейных принципал-агентских отношениях между странами - членами Европейского союза и наднациональными нормативными регуляторами. В теориях структурно-акторного подхода на вершине иерархии оказываются либо европейские бюрократы и чиновники, устанавливающие правила игры для стран - членов ЕС, либо национальные акторы и элитные группировки, которые стремятся скорректировать общеевропейский политический курс в свою пользу. Рассмотрение проблемы власти и авторитета в привязке к концепту государственной состоятельности демонстрирует тот факт, что для сторонников структурно-акторного подхода наиболее важен вопрос о том, кто стоит во главе системы распределения ресурсов и определения политического курса в рамках управленческой структуры Европейского союза.

Второй подход к изучению проблемы властных отношений в Европейском союзе выходит за пределы обозначенной дихотомии «принципал - агент» и рассматривает связи между национальным 
и наднациональным уровнями власти через призму теории консоциативной демократии. Для теоретиков консоциативного подхода наибольший интерес представляет вопрос о том, как будут аллоцироваться ресурсы и кто станет бенефициаром конкретного политического решения по итогам обсуждения в рамках европейских «больших коалиций». В отличие от работ структурно-акторного подхода, которые редуцируют отношения между странами - членами ЕС и наднациональным уровнем до двухуровневой иерархии, исследования сторонников идеи консоциативной демократии фокусируются на более специфических вопросах - проблемах горизонтальной и вертикальной подотчетности, демократического дефицита и многоуровневого авторитета.

\section{Список литературы}

Мельвиль А.Ю., Стукал Д.К., Миронюк М.Г. Траектории режимных трансформаций и типы государственной состоятельности // Полис. Политические исследования. - М., 2012. - № 2. - С. 8-30.

Стукал Д.К., Хавенсон Т.Е. Моделирование государственной состоятельности постсоциалистических стран // Политическая экспертиза: ПОЛИТЭКС. - СПб., 2012. - № 1. - C. 233-260.

Adler-Nissen R. Opting out of the European Union: diplomacy, sovereignty and European integration. - Cambridge: Cambridge univ. press, 2014. - $266 \mathrm{p}$.

Andeweg R.B. Consociational democracy // Annual Review of Political Science. - Palo Alto, 2000. - N 1. - P. 509-536.

Armingeon $K$. Interest intermediation: The cases of consociational democracy and corporatism. Comparative Democratic Politics. A Guide to Contemporary Theory and Research. - L.: Sage, 2002. - 165 p.

Attina $F$. The voting behaviour of the European Parliament members and the problem of the Europarties // European Journal of Political Research. - L., 1990. - N 5. P. 557-579.

Between power and plenty: Foreign economic policies of advanced industrial states / Ed. by P.J. Katzenstein. - Wisconsin: Univ. of Wisconsin press, 1978. - 344 p.

Billiet $S$. From GATT to the WTO: The internal struggle for external competences in the EU // JCMS: Journal of Common Market Studies. - L., 2006. - N 5. - P. 899-919.

Bogaards M. Democracy and Power-Sharing in Multinational States: Thematic Introduction // International Journal on Multicultural Societies. - 2006. - Vol. 8, N 2. P. 119-126.

Bogaards M., Crepaz M.M.L. Consociational interpretations of the European Union // European Union Politics. - Lisbon, 2002. - N 3. - P. 357-381.

Bringing the state back in / P.B. Evans, D. Rueschemeyer, T. Skocpol (eds.). - Cambridge: Cambridge univ. press, 1985. -404 p. 
Burgess M. Federalism and the European Union: the building of Europe, 1950-2000. L., 2002. -290 p.

Butenschøn N.A. Conflict management in plural societies: The consociational democracy formula // Scandinavian Political Studies. - L., 1985. - N 1/2. - P. 85-103.

Carlsnaes $W$. The agency-structure problem in foreign policy analysis // International studies quarterly. - Oxford, 1992. - N 3. - P. 245-270.

Checkel J.T. Why comply? Social learning and European identity change // International organization. - Cambridge, 2001. - N 3. - P. 553-588.

Consociational Democracy: Political Accommodation in Segmented Societies / Ed. by K. McRae. - Montreal, Quebec: McGill-Queen's univ. press, 1974. - $312 \mathrm{p}$.

Cooper I. The watchdogs of subsidiarity: National parliaments and the logic of arguing in the EU // JCMS: Journal of Common Market Studies. - L., 2006. - N 2. - P. 281-304.

Costa O., Foret F. The European Consociational Model: An Exportable Institutional Design? // European Foreign Affairs Review. - Amsterdam, 2005. - N 4. - P. 501-516.

Deliberating across deep divides / R.C. Luskin, I. O'Flynn, J.S. Fishkin, D. Russell // Political Studies. - Boston, 2014. - N 1. - P. 116-135.

Dixon P. The politics of conflict: A constructivist critique of consociational and civil society theories // Nations and Nationalism. - L., 2012. - N 1. - P. 98-121.

Fearon J.D. Bargaining, enforcement, and international cooperation // International organization. - Cambridge, 1998. - N 2. - P. 269-305.

Frognier A.P. The mixed nature of Belgian cabinets between majority rule and consociationalism // European Journal of Political Research. - L., 1988. - N 2. - P. 207-228.

Gabel M.J. The endurance of supranational governance: A consociational interpretation of the European Union // Comparative Politics. - N.Y.; Chicago, Ill., 1998. - P. 463-475.

Garry J. Potentially Voting across the Divide in Deeply Divided Places: Ethnic Catch All Voting in Consociational Northern Ireland // Political Studies. - Boston, 2014. - P. 2-19.

Gheyle N., De Ville F. Outside Lobbying and the Politicization of the Transatlantic Trade and Investment Partnership // Lobbying in the European Union. - Cham, 2019. P. 339-354.

Golub J. Sovereignty and subsidiarity in EU environmental policy // Political Studies. Boston, 1996. - N 4. - P. 686-703.

Haas P.M. Compliance with EU directives: insights from international relations and comparative politics // Journal of European Public Policy. - Oxford, 1998. - N 1. P. 17-37.

Haddad S. Lebanon: from consociationalism to conciliation // Nationalism and Ethnic Politics. - Oxford, 2009. - N 3/4. - P. 398-416.

Heidbreder E.G. Structuring the European administrative space: Policy instruments of multi-level administration // Journal of European Public Policy. - Oxford, 2011. N 5. - P. 709-727.

Hille P., Knill C. 'It's the Bureaucracy, Stupid' The Implementation of the Acquis Communautaire in EU Candidate Countries, 1999-2003 // European Union Politics. L., 2006. - N 4. - P. 531-552. 
Horowitz D.L. Conciliatory institutions and constitutional processes in post-conflict states // William and Mary Law Review. - Williamsburg, VA, 2008. - N 49. P. 1213-1248.

Horowitz D.L. Ethnic Groups in Conflict. - Berkeley: University of California Press, 1985. $-711 \mathrm{p}$.

Hug S., Schulz T. Referendums in the EU's constitution building process // The Review of International Organizations. - L., 2007. - N 2. - P. 177-218.

Jérôme B., Vaillant N.G. The French rejection of the European constitution: An empirical analysis // European Journal of Political Economy. - Amsterdam, 2005. - N 4. P. 1085-1092.

Jervis $R$. Cooperation under the security dilemma // World politics. - Baltimore, Md., 1978. - N 2. - P. 167-214.

Jolly M. A demos for the European Union? // Politics. - L., 2005. - N 1. - P. 12-18.

Jordan A., Jeppesen T. EU environmental policy: adapting to the principle of subsidiarity? // European Environment. - Hoboken, NJ, 2000. - N 2. - P. 64-74.

Kaiser A. Alternation, inclusion and the European Union // European Union Politics. L., 2002. - N 4. - P. 445-458.

Kant I. Perpetual peace: A philosophical sketch. - Cambridge: Cambridge univ. press, 1970. -59 p.

Keohane R.O. After hegemony: Cooperation and discord in the world political economy. - Princeton, NJ: Princeton univ. press, 2005. - $320 \mathrm{p}$.

Keohane R.O., Moravcsik A., Slaughter A.M. Legalized dispute resolution: Interstate and transnational // International organization. - Cambridge, 2000. - N 3. - P. 457-488.

Kohler-Koch B. Changing patterns of interest intermediation in the European Union // Government and Opposition. - Cambridge, 1994. - N 2. - P. 166-180.

Kohler-Koch B. Organized Interests in the EC and the European Parliament // European Integration online Papers (EIoP). - Wien, 1997. - N 9. - P. 1-15.

Kraus $P$. Legitimacy, democracy and diversity in the European Union // International Journal on Multicultural Societies. - Paris, 2006. - N 2. - P. 203-244.

Legitimacy and the European Union: The contested polity / T. Banchoff, M. Smith (eds.). - L.: Routledge, 2005. -240 p.

Lehmbruch G. Consociational democracy and corporatism in Switzerland // Publius: The journal offederalism. - 1993. - Vol. 23, N 2. - P. 43-60

Lijphart A. Consociational democracy // World politics. - Baltimore, Md., 1969. - N 2. P. 207-225.

Linos $K$. How can international organizations shape national welfare states? Evidence from compliance with European Union directives // Comparative Political Studies. Thousand Oaks, CA, 2007. - N 5. - P. 547-570.

Magnette P. European governance and civic participation: beyond elitist citizenship? // Political studies. - Boston, 2003. - N 1. - P. 144-160.

Mendrinou M. Non compliance and the European commission's role in integration // Journal of European Public Policy. - Oxford, 1996. - N 1. - P. 1-22.

Mitchell R.B. Regime design matters: intentional oil pollution and treaty compliance // International organization. - Cambridge, 1994. - N 3. - P. 425-458. 
Moravcsik A. Negotiating the Single European Act: national interests and conventional statecraft in the European Community // International organization. - Cambridge, 1991. - N 1. - P. 19-56.

Morgenthau H.J. Politics Among Nations: the Struggle for Power and Peace. - N.Y.: Knopf, 1950. - $618 \mathrm{p}$.

Noel S.J.R. From power sharing to democracy: Post-conflict institutions in ethnically divided societies. - Montreal, Quebec: McGill-Queen's univ. press, 2005. - $312 \mathrm{p}$.

Nye J.S. Peace in parts: Integration and conflict in regional organization. - Boston: Little, Brown, 1971. - $136 \mathrm{p}$.

Paraskevopoulos C.J. Social capital, institutional learning and European regional policy: Evidence from Greece // Regional \& Federal Studies. - L., 1998. - N 3. - P. 31-64.

Peters B.G. Agenda setting in the European Community // Journal of European Public Policy. - Oxford, 1994. - N 1. - P. 9-26.

Pollack M.A. Principal-Agent Analysis and International Delegation: Red Herrings, Theoretical Clarifications and Empirical Disputes // SSRN Electronic Journal. - 2007. P. 1-25.

Reilly $B$. Institutional designs for diverse democracies: Consociationalism, centripetalism and communalism compared // European Political Science. - L., 2012. - N 2. P. 259-270.

Richardson K. Big business and the European agenda. - Sussex: Sussex European Institute, 2000. - 30 p. - (SEI working paper; N 35).

Sandholtz W., Stone Sweet A. European Integration and Supranational Governance 1 st Edition. - Oxford: Oxford University Press. $-400 \mathrm{p}$.

Schneider G., Finke D., Baltz K. With a little help from the state: interest intermediation in the domestic pre-negotiations of EU legislation // Journal of European Public Policy. Oxford, 2007. - N 3. - P. 444-459.

Selway J., Templeman K. The myth of consociationalism? Conflict reduction in divided societies // Comparative Political Studies. - Thousand Oaks, CA, 2012. - N 12. P. $1542-1571$.

Simmons B.A. Compliance with international agreements // Annual review of political science. - N.Y., 1998. - N 1. - P. 75-93.

Simonsen S.G. Addressing ethnic divisions in post-conflict institution-building: Lessons from recent cases // Security Dialogue. - L., 2005. - N 3. - P. 297-318.

Smooha S., Hanf T. Conflict-regulation in deeply divided societies // International Journal of Comparative Sociology. - L., 1992. - N 33 (1/2). - P. 26-47.

Sustainable Democracy / Ed. by A. Przeworski. - Cambridge: Cambridge univ. press, 1995. - $155 \mathrm{p}$.

Sustainable peace: Power and democracy after civil wars / P.G. Roeder, D.S. Rothchild (eds.). - Ithaca, NY: Cornell univ. press, 2005. - 406 p.

Sweet A.S., Sandholtz W. European integration and supranational governance // Journal of European public policy. - Oxford, 1997. - N 3. - P. 297-317.

Tallberg J. Paths to compliance: Enforcement, management, and the European Union // International organization. - Cambridge, 2002. - N 3. - P. 609-643.

Taylor R. Consociational theory. - L., 2009. -416 p. 
Toonen T.A.J., Steunenberg B., Voermans W. Saying No to a European Constitution: Dutch Revolt, Enigma or Pragmatism? // Zeitschrift für Staats-und Europawissenschaften. - Munchen, 2006. - N 4. - P. 594-619.

Toshkov D. Transposition of EU social policy in the new member states // Journal of European Social Policy. - L., 2007. - N 4. - P. 335-348.

Trauner F. Post-accession compliance with EU law in Bulgaria and Romania: a comparative perspective // Post-accession compliance in the EU's new member states, European Integration online Papers (EIoP) / F. Schimmelfennig, F. Trauner (eds.).2009. - Special Issue 2, Vol. 13, Art. 21. - P. 1-18. - Mode of access: http://eiop.or.at/eiop/texte/2009-021a.htm (accessed: 22.05.2019.)

Treib $O$. The voter says no, but nobody listens: causes and consequences of the Eurosceptic vote in the 2014 European elections // Journal of European Public Policy. Oxford, 2014. - N 10. - P. 1541-1554.

Tsebelis $G$. Decision making in political systems: Veto players in presidentialism, parliamentarism, multicameralism and multipartyism // British journal of political science. - L., 1995. - N 3. - P. 289-325.

Volpi $V$. Why Europe will not run the 21 st century: reflections on the need for a new European federation. - Cambridge: Cambridge Scholars Publishing, 2011. - 275 p.

Waltz K.N. Neorealism and its Critics. - N.Y.: Columbia univ. press, 1986. -378 p.

\section{A.B. Sorbale* \\ Power and authority in the European Union: «Kings of the hill» and «grand coalitions»}

Abstract. How is power and authority distributed in the European Union? What role does state capacity play in the framework of relations between the levels of authority in the EU? In this article, we seek to answer these questions by addressing two key approaches to the analysis of the European Union as a multi-level system of governance: the structural-actor approach and the approach of consociational democracy. While supporters of the structural-actor approach perceive the EU as a hierarchical system, where one of the levels of power is always in a position of dominance and can dictate its rules of the game, the theoreticians of European consociationalism are more interested in the issues related to the decision-making process under the conditions of «grand coalitions», horizontal and vertical accountability and democratic deficit.

Keywords: power; authority; structural-actor approach; consociational democracy; state capacity.

For citation: Sorbale A.B. Power and authority in the European Union: «Kings of the hill» and «grand coalitions». Political science (RU). 2019, N 3, P. 200-221. DOI: http://www.doi.org/10.31249/poln/2019.03.11

* Sorbale Alexey, National Research University Higher School of Economics (St. Petersburg, Russia), e-mail: e-mail: asorbale@hse.ru 


\section{References}

Adler-Nissen R. Opting out of the European Union: diplomacy, sovereignty and European integration. Cambridge: Cambridge univ. press, 2014, 266 p.

Andeweg R.B. Consociational democracy. Annual Review of Political Science. Palo Alto, 2000, N 1, P. 509-536.

Armingeon K. Interest intermediation: The cases of consociational democracy and corporatism. Comparative Democratic Politics. A Guide to Contemporary Theory and Research. L.: Sage, 2002, 165 p.

Attina F. The voting behaviour of the European Parliament members and the problem of the Europarties. European Journal of Political Research. 1990, N 5, P. 557-579.

Between power and plenty: Foreign economic policies of advanced industrial states. Ed. by P.J. Katzenstein. Univ. of Wisconsin press, 1978, 344 p.

Billiet S. From GATT to the WTO: The internal struggle for external competences in the EU. JCMS: Journal of Common Market Studies. 2006, N 5, P. 899-919.

Bogaards M. Democracy and Power-Sharing in Multinational States: Thematic Introduction. International Journal on Multicultural Societies. 2006, Vol. 8, N 2, P. 119-126.

Bogaards M., Crepaz M.M. L. Consociational interpretations of the European Union. European Union Politics. 2002, N 3, P. 357-381.

Bringing the state back in. Ed. by P.B. Evans, D. Rueschemeyer, T. Skocpol. Cambridge univ. press, 1985, $404 \mathrm{p}$.

Burgess M. Federalism and the European Union: the building of Europe, 1950-2000. L.: Routledge, 2002, 290 p.

Butenschøn N.A. Conflict management in plural societies: The consociational democracy formula. Scandinavian Political Studies. 1985, N 1-2, P. 85-103.

Carlsnaes W. The agency-structure problem in foreign policy analysis. International studies quarterly. 1992, N 3, P. 245-270.

Checkel J.T. Why comply? Social learning and European identity change. International organization. 2001, N 3, P. 553-588.

Consociational Democracy: Political Accommodation in Segmented Societies. Ed. by K. McRae. Montreal, Quebec: McGill-Queen's univ. press, 1974, 312 p.

Cooper I. The watchdogs of subsidiarity: National parliaments and the logic of arguing in the EU. JCMS: Journal of Common Market Studies. 2006, N 2, P. 281-304.

Costa O., Foret F. The European Consociational Model: An Exportable Institutional Design? European Foreign Affairs Review. 2005, N 4, P. 501-516.

Dixon P. The politics of conflict: A constructivist critique of consociational and civil society theories. Nations and Nationalism. 2012, N 1, P. 98-121.

Fearon J.D. Bargaining, enforcement, and international cooperation. International organization. 1998, N 2, P. 269-305.

Frognier A.P. The mixed nature of Belgian cabinets between majority rule and consociationalism. European Journal of Political Research. 1988, N 2, P. 207-228.

Gabel M.J. The endurance of supranational governance: A consociational interpretation of the European Union. Comparative Politics. 1998, P. 463-475.

Garry J. Potentially Voting across the Divide in Deeply Divided Places: Ethnic Catch-All Voting in Consociational Northern Ireland. Political Studies. 2014, P. 2-19. 
Gheyle N., De Ville F. Outside Lobbying and the Politicization of the Transatlantic Trade and Investment Partnership. Lobbying in the European Union. 2019, P. 339-354.

Golub J. Sovereignty and subsidiarity in EU environmental policy. Political Studies. 1996, N 4, P. 686-703.

Haas P.M. Compliance with EU directives: insights from international relations and comparative politics. Journal of European Public Policy. 1998, N 1, P. 17-37.

Haddad S. Lebanon: from consociationalism to conciliation. Nationalism and Ethnic Politics. 2009, N 3-4, P. 398-416.

Heidbreder E.G. Structuring the European administrative space: Policy instruments of multi-level administration. Journal of European Public Policy. 2011, N 5, P. 709-727.

Hille P., Knill C. 'It's the Bureaucracy, Stupid' The Implementation of the Acquis Communautaire in EU Candidate Countries, 1999-2003. European Union Politics. 2006, N 4, P. 531-552.

Horowitz D.L. Conciliatory institutions and constitutional processes in post-conflict states. William and Mary Law Review. 2008, N 49, P. 1213-1248.

Horowitz D.L. Ethnic Groups in Conflict. Berkeley: University of California Press, $1985,711 \mathrm{p}$.

Hug S., Schulz T. Referendums in the EU's constitution building process. The Review of International Organizations. 2007, N 2, P. 177-218.

Jérôme B., Vaillant N.G. The French rejection of the European constitution: An empirical analysis. European Journal of Political Economy. 2005, N 4, P. 1085-1092.

Jervis R. Cooperation under the security dilemma. World politics. Baltimore, Md., 1978, N 2, P. 167-214.

Jolly M. A demos for the European Union? Politics. 2005, N 1, P. 12-18.

Jordan A., Jeppesen T. EU environmental policy: adapting to the principle of subsidiarity? European Environment. 2000, N 2, P. 64-74.

Kaiser A. Alternation, inclusion and the European Union. European Union Politics. 2002, N 4, P. 445-458.

Kant I. Perpetual peace: A philosophical sketch. Cambridge: Cambridge univ. press, 1970,59 p.

Keohane R.O. After hegemony: Cooperation and discord in the world political economy. Princeton, NJ: Princeton univ. press, 2005, 320 p.

Keohane R.O., Moravcsik A., Slaughter A.M. Legalized dispute resolution: Interstate and transnational. International organization. 2000, N 3, P. 457-488.

Kohler-Koch B. Changing patterns of interest intermediation in the European Union. Government and Opposition. 1994, N 2, P. 166-180.

Kohler-Koch B. Organized Interests in the EC and the European Parliament. European Integration online Papers (EIoP). 1997, N 9, P. 1-15.

Kraus P. Legitimacy, democracy and diversity in the European Union. International Journal on Multicultural Societies. 2006, N 2, P. 203-244.

Legitimacy and the European Union: The contested polity / T. Banchoff, M. Smith (eds.). Routledge, 2005, 240 p.

Lehmbruch G. Consociational democracy and corporatism in Switzerland. Publius: The journal of federalism. 1993, Vol. 23, N 2, P. 43-60.

Lijphart A. Consociational democracy. World politics. 1969, N 2, P. 207-225. 
Linos K. How can international organizations shape national welfare states? Evidence from compliance with European Union directives. Comparative Political Studies. 2007, N 5, P. 547-570.

Luskin R.C. et al. Deliberating across deep divides. Political Studies. Boston, 2014, N 1, P. 116-135.

Magnette P. European governance and civic participation: beyond elitist citizenship? Political studies. 2003, N 1, P. 144-160.

Melville A. Yu., Stukal D.K., Mironyuk M.G. State consistency, democracy and democratization (on the example post-communist countries). Polis. Political Studies. 2012, N 2, P. 8-30. (In Russ.)

Mendrinou M. Non compliance and the European commission's role in integration. Journal of European Public Policy. 1996, N 1, P. 1-22.

Mitchell R.B. Regime design matters: intentional oil pollution and treaty compliance. International organization. 1994, N 3, P. 425-458.

Moravcsik A. Negotiating the Single European Act: national interests and conventional statecraft in the European Community. International organization. 1991, N 1, P. 19-56.

Morgenthau H.J. Politics Among Nations: the Struggle for Power and Peace. N.Y.: Knopf, 1950, $618 \mathrm{p}$.

Noel S.J.R. From power sharing to democracy: Post-conflict institutions in ethnically divided societies. Montreal, Quebec: McGill-Queen's univ. press, 2005, 312 p.

Nye J.S. Peace in parts: Integration and conflict in regional organization. Boston: Little, Brown, 1971.

Paraskevopoulos C.J. Social capital, institutional learning and European regional policy: Evidence from Greece. Regional \& Federal Studies. 1998, N 3, P. 31-64.

Peters B.G. Agenda setting in the European Community. Journal of European Public Policy. 1994, N 1, P. 9-26.

Pollack M.A. Principal-Agent Analysis and International Delegation: Red Herrings, Theoretical Clarifications and Empirical Disputes. SSRN Electronic Journal. 2007, P. $1-25$.

Reilly B. Institutional designs for diverse democracies: Consociationalism, centripetalism and communalism compared. European Political Science. 2012, N 2, P. 259-270.

Richardson K. Big business and the European agenda. Sussex: Sussex European Institute, 2000, 30 p. (SEI working paper No. 35)

Sandholtz W., Stone Sweet A. European Integration and Supranational Governance 1 st Edition. Oxford: Oxford University Press, $400 \mathrm{p}$.

Schneider G., Finke D., Baltz K. With a little help from the state: interest intermediation in the domestic pre-negotiations of EU legislation. Journal of European Public Policy. 2007, N 3, P. 444-459.

Selway J., Templeman K. The myth of consociationalism? Conflict reduction in divided societies. Comparative Political Studies. 2012, N 12, P. 1542-1571.

Simmons B.A. Compliance with international agreements. Annual review of political science. 1998, N 1, P. 75-93.

Simonsen S.G. Addressing ethnic divisions in post-conflict institution-building: Lessons from recent cases. Security Dialogue. 2005, N 3, P. 297-318. 
Smooha S., Hanf T. Conflict-regulation in deeply divided societies. International Journal of Comparative Sociology. 1992, N 33 (1-2), P. 26-47

Stukal D.K., Havenson T.E. Modeling State Capacity in Post-Socialist Countries. Political Expertise: POLITEX. 2012, N 1, P. 233-260. (In Russ.)

Sustainable Democracy. Ed. by A. Przeworski. Cambridge: Cambridge univ. press, $1995,155 \mathrm{p}$.

Sustainable peace: Power and democracy after civil wars. Ed. by P.G. Roeder, D.S. Rothchild. Ithaca, NY: Cornell univ. press, 2005, 406 p.

Sweet A.S., Sandholtz W. European integration and supranational governance. Journal of European public policy. 1997, N 3, P. 297-317.

Tallberg J. Paths to compliance: Enforcement, management, and the European Union. International organization. 2002, N 3, P. 609-643.

Taylor R. Consociational theory. Routledge, 2009, 416 p.

Toonen T.A.J., Steunenberg B., Voermans W. Saying No to a European Constitution: Dutch Revolt, Enigma or Pragmatism? Zeitschrift für Staats-und Europawissenschaften. 2006, N 4, P. 594-619.

Toshkov D. Transposition of EU social policy in the new member states. Journal of European Social Policy. 2007, N 4, P. 335-348.

Trauner F. Post-accession compliance with EU law in Bulgaria and Romania: a comparative perspective. In: Post-accession compliance in the EU's new member states, European Integration online Papers (EIoP). Ed. by F. Schimmelfennig, F. Trauner. 2009, Special Issue 2, Vol. 13, Art. 21, P. 1-18, Mode of access: http://eiop.or.at/eiop/texte/2009-021a.htm (accessed: 22.05.2019.)

Treib O. The voter says no, but nobody listens: causes and consequences of the Eurosceptic vote in the 2014 European elections. Journal of European Public Policy. 2014, N 10, P. 1541-1554.

Tsebelis G. Decision making in political systems: Veto players in presidentialism, parliamentarism, multicameralism and multipartyism. British journal of political science. 1995, N 3, P. 289-325.

Volpi V. Why Europe will not run the 21 st century: reflections on the need for a new European federation. Cambridge: Cambridge Scholars Publishing, 2011, 275 p.

Waltz K.N. Neorealism and its Critics. N.Y.: Columbia univ. press, 1986, 378 p. 